\title{
Suplementação de Bovinos em Pastagens de Coastcross (Cynodon dactylon (L.) Pers) no Inverno $^{1}$
}

\author{
Paulo Emílio Fernandes Prohmann², Antonio Ferriani Branco ${ }^{3}$, Ulysses Cecato ${ }^{3}$, Clóves \\ Cabreira Jobim ${ }^{3}$, Kátia Cylene Guimarães ${ }^{2}$, Rosemeri Aparecida Ferreira ${ }^{4}$
}

RESUMO - O experimento foi realizado no município de Luiziana, noroeste do Estado do Paraná, no período de junho a outubro de 2000. Foram utilizados 24 novilhos inteiros, com nove meses de idade e peso inicial médio de 223 kg, pertencentes a dois grupos

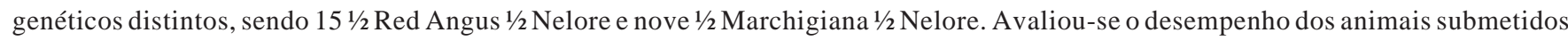
a três formas de suplementação e a qualidade e produtividade da forragem. A área experimental foi constituída por quatro piquetes, sendo três de Coastcross (Cynodon dactylon (L.) Pers), com área total de 7,35 ha e um de Aveia (Avena strigosa Schreb), consorciada com Azevém (Lolium multiflorum Lam), totalizando 2 ha. Os novilhos permaneceram em pastagens de Coastcross e foram submetidos a três tratamentos: pastejo em Aveia + Azevém (AA) por quatro horas diárias; suplemento (S) a 1,2\% do peso vivo; suplemento + lasalocida (SL) a 1,2\% do peso vivo. Estimativas da biomassa e da qualidade das forrageiras foram realizadas. Decorridos 112 dias experimentais, S e SL não apresentaram diferença para ganho médio diário (GMD = 1,063 kg e 1,026 kg, respectivamente), mas foram superiores a AA $(0,856 \mathrm{~kg})$. Concluiu-se que a adição de lasalocida ao suplemento não produziu diferença no desempenho dos animais. Estes resultados comprovam que animais mantidos em pastagem de Coastcross, com quatro horas de pastejo em pastagem anual de inverno ou com suplementação (1,2\% do peso vivo), independentemente da adição de ionóforo, apresentaram elevados ganhos na época crítica do ano.

Palavras-chave: aveia, azevém, desempenho, lasalocida, novilhos, pastejo

\section{Cattle Supplementation on Coastcross Pasture (Cynodon dactylon (L.) Pers) during the Winter}

\begin{abstract}
This trial was carried out in Luiziana, Northwest of Paraná, from June to October 2000. Twenty-four animals with $223 \mathrm{~kg}$ of initial body weight and nine months old, from two different genetic groups, $1 / 2$ Red Angus $1 / 2$ Nellore (15) and 1/2 Marchigiana $1 / 2$ Nellore (9), were used. Animal performance was evaluated, under grazing conditions of Coastcross (Cynodon dactylon (L.) Pers) and three types of supplementation: grazing Oat + Ryegrass pasture (OR) for four hours/day; $1.2 \%$ of body weight (BW) supplement (S); $1.2 \%$ of BW supplement + lasalocid (SL). The experimental area consisted of four padocks: three of Coastcross, with 7.35 ha of total area; and one of Oat (Avena strigosa Schreb) and Ryegrass (Lolium multiflorum Lam), with two ha. Pasture accumulation and quality were evaluated. After 112 days of experimental period, average daily gain did not show any difference between S and SL (1.063 kg and $1.026 \mathrm{~kg}$, respectively), but both were superior than OR $(0.856 \mathrm{~kg})$. Lasalocid addition to supplement did not improve animal performance. These results show that even during the dry period, supplementation (1.2\% of BW), with or without lasalocid, or winter pasture, can result in high liveweight.
\end{abstract}

Key Words: grazing, lasalocid, oat, performance, Ryegrass, steers

\section{Introdução}

A estacionalidade na produção das forrageiras tropicais propicia grande disponibilidade de matéria seca no período das águas (primavera/verão) e escassez no período seco (outono/inverno), impedindo o desenvolvimento contínuo e uniforme dos animais durante o ano. No outono e inverno, há grande aumento no percentual de massa seca e fibra indigestível e queda abrupta do conteúdo de proteína e da digestibilidade da forragem, sendo que, nestas condições, o consumo voluntário é reduzido a níveis mínimos (Peruchena, 1999).

Numerosas pesquisas têm indicado que a

\footnotetext{
${ }^{1}$ Parte da dissertação do primeiro autor apresentada à Universidade Estadual de Maringá para a obtenção do título de "Mestre em Zootecnia".

${ }^{2}$ Estudante de Pós-Graduação em Zootecnia - UEM - Av. Colombo, 5790 - CEP: 87020-900. E.mail: pauloprohmann@yahoo.com.br; cylene25@hotmail.com

${ }^{3}$ Professores do Departamento de Zootecnia - Bolsistas pesquisadores, CNPq - UEM - Av. Colombo, 5790 - CEP: $87020-900$. E.mail: afbranco@uem.br; ucecato@uem.br, ccjobim@uem.br.

${ }^{4}$ Estudante de Graduação em Zootecnia - UEM - Av. Colombo, 5790 - CEP: 87020-900. Maringá-PR. E-mail: roseaferreira@bol.com.br.
} 
suplementação protéica, em dietas à base de forragens de baixa qualidade, pode melhorar a produção de bovinos de corte (DelCurto et al., 1990). Segundo Thiago (1999), maior produtividade dos sistemas de produção de carne a pasto só será alcançada se houver ajuste entre a curva sazonal de oferta de nutrientes das pastagens e a crescente demanda de nutrientes pelo animal. Este fato é possível por meio do uso da suplementação alimentar, desde que esta apresente relação custo:benefício favorável.

$\mathrm{Na}$ avaliação de pastagens com animais em pastejo, as respostas referentes ao animal são de fácil observação, mas, freqüentemente, o mesmo não ocorre com a caracterização da pastagem e, em consequência, omite-se a força explicativa potencial das variáveis que influenciam a resposta animal e que tem utilidade para o produtor (Maraschin, 1999).

Segundo Pedreira et al. (2001), a intensidade e frequência de pastejo, espécie animal, método de apreensão da forragem, pisoteio, deposição de fezes e urina e, eventualmente, de saliva podem causar alterações substanciais na persistência, produtividade e composição botânica do dossel. Sempre que as relações entre a estrutura da pastagem e o processo de pastejo dos animais são abordadas, registram-se a escassez dessas informações para as condições de pastagens tropicais (Carvalho et al., 2001). Pesquisas sobre produção e qualidade de forragens, geralmente, baseiam-se em estudos com canteiros, sem a presença animal.

Quando a forragem possui teor de proteína bruta (PB) inferior a 6 - $7 \%$, seu consumo declina, assim como sua digestibilidade (Moore \& Kunkle, 1998). Estes autores descrevem que a relação NDT:PB pode fornecer informações importantes sobre o equilíbrio da dieta. Altas relações NDT:PB (acima de sete) indicam deficiência protéica, fazendo-se necessária a suplementação. É importante salientar que nem sempre uma relação igual à sete indica qualidade, podendo demonstrar que ambos os nutrientes são escassos.

Os ionóforos são antibióticos amplamente utilizados em animais confinados com o propósito de melhorar a eficiência alimentar e, nos últimos anos, passaram a ser pesquisados quanto ao desempenho de bovinos em pastagens. Os ionóforos mais utilizados são a monensina sódica e a lasalocida sódica.

As pastagens cultivadas de inverno são alternativas para corrigir a carência alimentar dos animais nesse período, aumentando o ganho animal e por área. Em contraste, as pastagens tropicais, neste mesmo período, apresentam baixa produção de MS e baixa qualidade, reduzindo o desempenho dos animais. Segundo Laer \& Maia (1999), o uso da consorciação de Aveia preta com Azevém, tem sido adotado de forma crescente pelos produtores do sul do Brasil, por aliar a precocidade de produção de forragem da Aveia preta com a qualidade de forragem e ciclo mais tardio do Azevém, estendendo-se, assim, o período de pastejo.

Este trabalho foi conduzido com o objetivo de avaliar o desempenho de novilhos mestiços inteiros, em pastagens de Coastcross (Cynodon dactylon (L.) Pers), submetidos a três formas de suplementação no inverno, avaliando-se também a qualidade e produtividade da forragem.

\section{Material e Métodos}

O experimento foi realizado na fazenda Dona Elisa, situada no município de Luiziana, noroeste do estado do Paraná, no período de junho a outubro de 2000. O solo da região é classificado como Latossolo Vermelho Escuro (Rauen et al., 1996) e o clima é caracterizado como Subtropical Úmido Mesotérmico (Secretaria da Agricultura e do Abastecimento do Estado do Paraná, 2000).

A área experimental foi dividida com cerca elétrica de dois fios e foi constituída por quatro piquetes: três de Coastcross (Cynodon dactylon (L.) Pers) e um de Aveia (Avena strigosa Schreb) consorciada com Azevém (Lolium multiflorum Lam). A pastagem de Coastcross, estabelecida há mais de três anos, possuía área total de 7,35 ha, e foi dividida em piquetes de 2,6; 2,45; e 2,3 ha/piquete. O piquete de Aveia e Azevém implantado no mês de maio apresentava área total de dois hectares. A água foi disponibilizada em bebedouros com bóia, os suplementos foram fornecidos em cochos de plástico (aproximadamente 0,5 metro/animal) e o sal mineral em cochos de madeira (aproximadamente 13 centímetros/animal).

A área foi adubada com base nos resultados de análise do solo. A adubação com fósforo e potássio foi realizada em abril de 2000, em cobertura, na forma de superfosfato simples e cloreto de potássio, respectivamente, em uma aplicação, de $30 \mathrm{~kg} / \mathrm{ha}$ de $\mathrm{P}_{2} \mathrm{O}_{5}$ e $70 \mathrm{~kg} /$ ha de $\mathrm{K}_{2} \mathrm{O}$. A adubação nitrogenada (70 kg de N/ha) foi aplicada na forma de uréia em maio de 2000.

Foram utilizados 24 novilhos inteiros, devidamente identificados (brinco numerado), com nove meses de idade e peso inicial médio de $223 \mathrm{~kg}$, sendo 15 1⁄2 Red 
Angus $1 / 2$ Nelore e nove $1 / 2$ Marchigiana $1 / 2$ Nelore, correspondendo a oito novilhos por piquete.

Todos os novilhos permaneceram na pastagem de Coastcross e foram submetidos a três tratamentos: 1) pastejo em Aveia + Azevém (AA) por quatro horas diárias, fornecendo forragem suplementar; 2) suplemento (S) a $1,2 \%$ do peso vivo, com base na MS; 3) suplemento com lasalocida (SL) a 1,2\% do peso vivo, com base na MS. Os suplementos S e SL (Tabela 1) continham 25\% de PB e 78\% de NDT.

Os animais foram pesados, sem jejum prévio, no início do experimento (23/06) e, a partir desta data, a cada 28 dias (quatro períodos), totalizando 112 dias experimentais. Foram everminados em julho e setembro e vacinados contra pasteurolose em setembro.

Foi adotado o método de lotação contínua, com carga fixa dos três piquetes, usados simultaneamente. Entretanto, para reduzir a influência de diferenças de biomassa entre os piquetes, procedeu-se ao rodízio aleatório dos três lotes de novilhos pelos três piquetes a cada dez dias.

As avaliações das forragens (estimativas de biomassa residual de MS e da taxa de acúmulo diário de MS) foram realizadas a cada 28 dias, nas seguintes datas: 23/06, 21/07, 23/08, 22/09 e 10/10.

As estimativas de biomassa residual de matéria seca (BR) foram realizadas nos três piquetes, conforme o método da dupla amostragem (Wilm et al., 1949). Foram coletadas aleatoriamente quatro amostras de $0,25 \mathrm{~m}^{2}$ em cada piquete, cortadas rente ao solo, pesadas e secadas em estufas com ventilação forçada a $65^{\circ} \mathrm{C}$, por 72 horas. Antes do corte, foi estimada visualmente a matéria seca da biomassa da amostra. Utilizando-se os valores das amostras cortadas e estimadas visualmente, foi calculada a biomassa de forragem (em $\mathrm{kg} / \mathrm{ha}$ ) pela equação proposta por Gardner (1986).

No piquete cultivado com aveia consorciada com azevém, a estimativa foi realizada com o auxílio do disco medidor, nas mesmas datas, medindo 100 amostras de altura e coletando 12 amostras no piquete (amostras reais), cortadas rente ao solo correspondentes à área de circunferência do disco, pesadas e secas em estufas com ventilação forçada a $65^{\circ} \mathrm{C}$, por 72 horas. Correlacionou-se a média da altura com a relação entre as doze alturas reais e o peso destas amostras, de acordo com a equação: $\mathrm{Y}=\mathrm{a}+\mathrm{bh}$, em que: $\mathrm{Y}=$ produção de $\mathrm{MS} / \mathrm{ha} ; \mathrm{a}=$ constante geral; b = coeficiente de correlação; $\mathrm{h}$ = altura.

A estimativa da taxa de acúmulo diário de MS
(TAD) foi realizada por intermédio da equação proposta por Campbell (1966):

$$
\operatorname{TAD}_{j}=\frac{\mathrm{G}_{\mathrm{i}}-\mathrm{F}_{\mathrm{i}}-_{1}}{\mathrm{n}}
$$

em que: $\mathrm{TAD}_{\mathrm{j}}=$ taxa de acúmulo de matéria seca diária no período j, em kg MS/ha/dia; $\mathrm{G}_{\mathrm{i}}=$ matéria seca dentro das gaiolas no instante i, em kg MS/ha; $\mathrm{F}_{\mathrm{i}-1}=$ matéria seca fora das gaiolas no instante $\mathrm{i}-1$, em $\mathrm{kg} \mathrm{MS} / \mathrm{ha} ; \mathrm{n}$ = número de dias do período j. $\mathrm{O}$ acúmulo de MS (A) nos diferentes períodos experimentais foi calculada multiplicando-se o valor de TAD pelo número de dias do período.

A taxa de lotação (TL) foi calculada considerando a unidade animal (UA) como sendo $450 \mathrm{~kg}$ de PV, utilizando-se a seguinte fórmula:

$$
\mathrm{TL}=\frac{\text { UAt }}{\text { Área }}
$$

em que: $\mathrm{TL}=$ taxa de lotação, em UA/ha; UAt = unidade animal total; Área = área experimental total, em ha.

O cálculo da oferta de forragem (OF), foi realizado de acordo com a seguinte fórmula:

$$
\mathrm{OF}=\frac{(\mathrm{BRD}+\mathrm{TAD})}{\mathrm{PV}} \times 100
$$

em que: OF = oferta de forragem, em kg MS/100 kg $\mathrm{PV} /$ dia; $\mathrm{BRD}$ = biomassa residual diária, em kg MS/ ha/dia; TAD = taxa de acúmulo diário, em kg MS/ha/

Tabela 1 - Composição dos suplementos experimentais

Table 1 - Experimental supplements composition

\begin{tabular}{lcc}
\hline $\begin{array}{l}\text { Ingredientes } \\
\text { Ingredients }\end{array}$ & S & SL \\
\hline $\begin{array}{l}\text { Casca de soja, \% } \\
\text { Soybean hulls, \% }\end{array}$ & 70 & 70 \\
$\begin{array}{l}\text { Farelo de soja, \% } \\
\text { Soybean meal, \% }\end{array}$ & 25 & 25 \\
$\begin{array}{l}\text { Farelo de milho, \% } \\
\text { Corn meal, \% }\end{array}$ & 1 & 0,882 \\
$\begin{array}{l}\text { Sal mineral, \% } \\
\text { Minerals, \% }\end{array}$ & 2 & 2 \\
$\begin{array}{l}\text { Uréia, \% } \\
\text { Urea, \% } \\
\text { Lasalocida sódica, \% } \\
\text { Sodium lasalocid, \% }\end{array}$ & - & 2 \\
\hline S: suplement SL: suplemento & 2 & 0,118 \\
\hline
\end{tabular}

S: suplemento; SL: suplemento + lasalocida.

S: supplement: SL: supplement + lasalocid.

R. Bras. Zootec., v.33, n.3, p.801-810, 2004 
dia; $\mathrm{PV}=$ peso vivo dos animais, em kg/ha.

Após fracionar em sub-amostras (aproximadamente $50 \%$ do material), a forragem coletada na dupla amostragem e na avaliação com o disco medidor, fez-se a separação dos componentes estruturais: lâmina foliar (LF); bainha + colmo verde (BCV); e material morto (MM), dos quais se obteve o peso seco individual e o percentual de cada um. Os cálculos de LF/ha, $\mathrm{BCV} / \mathrm{ha}$ e MM/ha foram obtidos do percentual de LF, BCV e MM multiplicado pela biomassa residual na pastagem em cada data de coleta.

As análises para determinação da qualidade do pasto foram realizadas em cada componente estrutural (LF, BCV e MM). Foram utilizadas as amostras coletadas na dupla amostragem e na avaliação com disco medidor, em cada piquete. Analisou-se o teor de proteína bruta (PB), utilizando-se metodologia descrita por Silva (1990), e a fibra em detergente neutro (FDN) e fibra em detergente ácido (FDA) segundo Van Soest et al. (1991). As análises de digestibilidade in vitro da matéria orgânica (DIVMO) foram realizadas pela metodologia de Tilley \& Terry (1963), adaptada para o uso do rúmen artificial, desenvolvido por Ankom ${ }^{\circledR}$, conforme descrito por Garman et al. (1997). Os valores da DIVMO foram utilizados para estimar o NDT da pastagem, conforme equação descrita por Kunkle \& Bates (1998):

NDT $=$ MO $\{[26,8+0,595($ DIVMO $)] / 100\}$

em que: $\mathrm{NDT}=$ nutrientes digestíveis totais (\%); DIVMO = digestibilidade in vitro da matéria orgânica
(\%); MO = matéria orgânica (\%).

Os dados de ganho médio diário foram analisados seguindo o modelo estatístico abaixo:

$$
\mathrm{Y}_{\mathrm{ij}}=\mu+\mathrm{t}_{\mathrm{i}}+\mathrm{e}_{\mathrm{ij}}
$$

em que: $Y_{i j}=$ observação $j$, submetido ao tratamento $\mathrm{i} ; \mu=$ constante geral; $\mathrm{t}_{\mathrm{i}}=$ efeito do tratamento $\mathrm{i}$, com i variando de 1 a 3 ; $\mathrm{e}_{\mathrm{ij}}=$ erro aleatório.

Para comparação entre médias foi utilizado o teste de Tukey a 5\%.

\section{Resultados e Discussão}

Os dados de BR, A, TAD, OF e TL encontramse na Tabela 2. O valor máximo (7956 kg/ha) de BR foi obtido em 23/06 (Tabela 2), como resultado da vedação dos piquetes de Coastcross por 45 dias antes do início do experimento e foi superior $(\mathrm{P}<0,05)$ aos demais períodos. Na segunda avaliação, foi possível constatar grande redução (52\%) nos valores da BR, resultado da presença dos animais sob pastejo, e das condições climáticas adversas ao desenvolvimento forrageiro, não havendo crescimento neste período $(\mathrm{TA}=0)$. Ao final do mês de julho, ocorreram quedas bruscas de temperatura, totalizando oito geadas, prejudicando muito as condições da pastagem e fazendo com que, novamente, houvesse queda na BR em agosto (redução de 53\%), quando também não foi observado crescimento da forragem $(\mathrm{A}=0)$. Segundo Vilela \& Alvim (1998), quanto à resistência a invernos rigorosos, sabe-se que, no gênero Cynodon, o cultivar

Tabela 2 - Biomassa residual (BR), acúmulo (A), taxa de acúmulo diária (TAD), oferta de forragem (OF) e taxa de lotação $(T L)$ em pastos de Coastcross, no inverno

Table 2 - Residual biomass (RB), accumulation (A), daily accumulation rate (DAR), forage offer (FO), and stocking rate (SR) in Coastcross pastures, in the winter

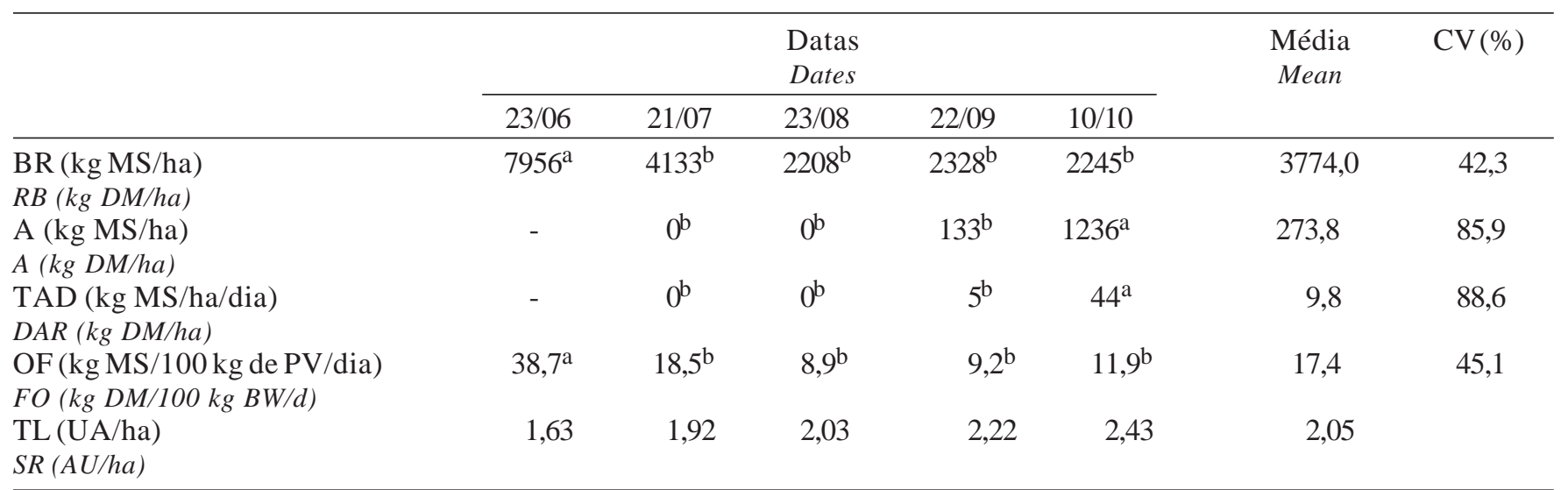

CV: coeficiente de variação (CV: coefficient of variation).

Médias, na linha, seguidas de diferentes letras diferem $(P<0,05)$ pelo teste Tukey.

Means, within a row, followed by different letters differ $(P<.05)$ by Tukey test.

R. Bras. Zootec., v.33, n.3, p.801-810, 2004 
Coastcross é o mais sensível a geadas fortes.

Nos mês de setembro, com a melhoria nas condições climáticas (aumento da temperatura e da precipitação pluviométrica), observou-se maior desenvolvimento da Coastcross, que foi expressivo no mês de outubro e superior $(\mathrm{P}<0,05)$ aos demais períodos, quando se observou acúmulo de $1236 \mathrm{~kg}$ MS/ha (44 kg MS/dia), mantendo a BR entre 2328 e $2245 \mathrm{~kg}$ MS/ha neste intervalo. Estes valores foram próximos aos preconizados por Corsi \& Martha Jr. (1998), segundo os quais a biomassa é de aproximadamente $2500 \mathrm{~kg}$ MS/ha, quando as plantas do gênero Cynodon são manejadas adequadamente.

As estimativas de oferta de forragem (OF) e taxa de lotação (TL) são apresentadas das na Tabela 2. Ao início do experimento, a oferta de forragem esteve muito acima $(\mathrm{P}<0,05)$ da média dos 112 dias experimentais, observando-se naquele momento o valor mais alto (38,7 kg MS/100 kg de PV). A oferta de forragem atingiu o menor valor $(8,9 \mathrm{~kg}$ MS/100 kg de PV) no final de agosto (23/08), ocasionado pelo inexistente crescimento forrageiro, aumento no PV dos animais e, conseqüentemente, do consumo. Nos meses de setembro e outubro, mesmo com a elevação do PV e da TL, a oferta de forragem manteve-se entre 9,2 e 11,9 kg MS/100 kg de PV, em virtude do crescimento da forragem, resultante das boas condições climáticas observadas neste período.

Observa-se, na Figura 1, a percentagem de LF, BCV e MM da forragem na estação seca, detalhando o perfil de cada um desses componentes. LF e BCV tiveram comportamentos muito semelhantes nos 112 dias de observação, pois apresentaram quedas percentuais durante o mês de julho, atingindo em agosto, níveis extremamente baixos. Tal observação decorre das condições climáticas adversas deste período, marcado por oito geadas e pelo pastejo seletivo dos novilhos por $\mathrm{LF}$ e $\mathrm{BCV}$, prejudicando o desenvolvimento adequado desses componentes. A elevação dos percentuais em setembro e outubro resultou da rebrota, quando as condições climáticas favoráveis permitiram o crescimento mais adequado da forragem. No mês de agosto, logo após as geadas, o MM representou quase a totalidade da planta (cerca de $89 \%$ ), pois em virtude de inexistir crescimento, houve muito material senescente e morto, tendo seu percentual reduzido em setembro e outubro.

A biomassa (kg/ha) de lâmina foliar (LF), bainha + colmo verde (BCV), material morto (MM), e a relação lâmina foliar/bainha + colmo verde (LF/BCV), encontram-se na Tabela 3. A biomassa de LF apresentou redução de $804 \mathrm{~kg}$ de $\mathrm{MS} / \mathrm{ha}(\mathrm{P}<0,05)$ no mês de julho em relação a junho, que foi atribuída ao início do pastejo e ao comportamento seletivo dos novilhos, pois, até então, a área encontrava-se vedada. Nova redução $(\mathrm{P}<0,05)$ na $\mathrm{LF}$ (494 kg de MS/ha) ocorreu entre os meses de julho e agosto, em virtude do consumo e da ocorrência de geadas. Entretanto, com condições climáticas favoráveis, a partir de setembro, houve um acréscimo na produção de LF (295kg/ MS/ha em setembro e $165 \mathrm{~kg} / \mathrm{MS} / \mathrm{ha}$ em outubro), ocorrendo o mesmo comportamento para a produção de BCV, alterando apenas os valores. A relação LF/BCV manteve-se abaixo de 0,40 nos três primeiros meses, alcançando valores mais elevados nos meses seguintes, em virtude do vigor da rebrota, ocasionando melhoria do valor nutritivo da planta forrageira devido à maior relação $\mathrm{LF} / \mathrm{BCV}$.

As médias percentuais de PB da LF, BCV e MM, foram de 18,4, 7,1 e 5,0\%, respectivamente (Tabela 4). Em agosto e setembro, a PB da LF alcançou valores elevados, resultado da adubação nitrogenada realizada, concentrando muito esse elemento na pequena quantidade de LF existente. Dados qualitativos sobre os componentes da forragem são escassos, dificultando comparações entre trabalhos. Utilizando-se os dados produção de cada componente da planta (Tabela 3) e considerando a composição química de cada um (Tabela 4), pôde-se

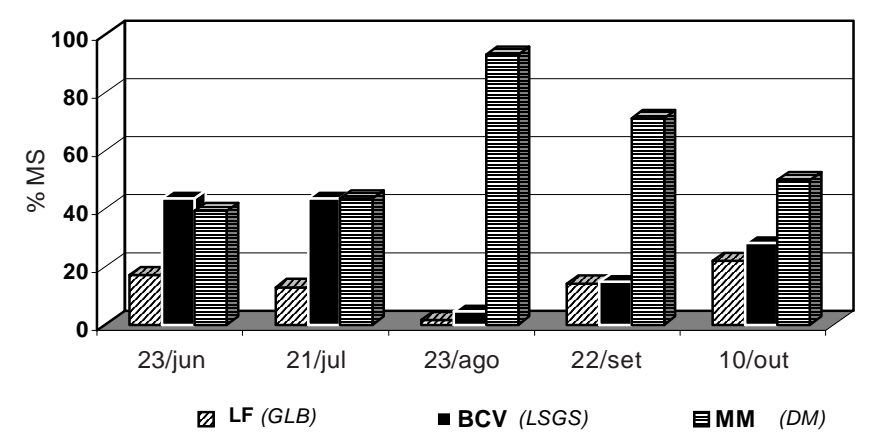

Figura 1 - Proporção dos componentes estruturais da Coastcross durante o inverno: lâmina foliar (LF); bainha + colmo verde (BCV) e material morto (MM).

Figure 1 - Structural components proportion of Coastcross pasture during the winter: green leaf blade (GLB); leaf sheath + green stem (LSGS); and dead material (DM). 
estimar a composição química da planta inteira. O valor médio para PB na planta inteira foi de 7\%, considerado por Moore et al. (1991) como mínimo para suprir as necessidades das bactérias ruminais.

A média de FDN ficou em torno de 61,9; 73,5 e $80,3 \%$ para a LF, BCV e MM e a planta inteira esteve com média de 76,6\%, sendo o maior valor no mês de agosto (81,3\%). Da mesma forma como ocorreu com FDN, os valores médios de FDA foram menores para LF (27,2\%) e maiores para a MM (44,7\%), com o BCV apresentando, em média, 39,6\%. A FDA da planta inteira alcançou valor médio de $41,6 \%$, sendo este um fator negativo, pois, de acordo com Nussio et al.
(1998), forragens com valores de FDA acima de 40\% apresentam baixo consumo.

As médias do NDT da LF, BCV e MM foram de 64,7, 55,8 e $44 \%$. A média da planta inteira ficou bem abaixo das médias obtidas pela LF e BCV, em virtude da grande proporção de MM, atingindo valor próximo de 49,9\%.

A relação NDT:PB da LF manteve-se, em todos os períodos, abaixo de sete, o que, segundo Moore \& Kunkle (1998), indica balanço adequado entre NDT e PB. É importante a análise desta relação na LF, uma vez que este é o componente mais procurado pelos bovinos no momento do pastejo. Fazendo a mesma relação, desta vez com a planta inteira, o resultado

Tabela 3 - Biomassa de lâmina foliar (LF), bainha + colmo verde (BCV), material morto (MM) e a relação LF/BCV da Coastcross, no inverno

Table 3 - Green leaf blade (GLB), leaf sheath + green stem (LSGS), dead material biomass $(D M)$, and GLB/LSGS ratio of Coastcross in the winter

\begin{tabular}{|c|c|c|c|c|c|c|c|}
\hline & \multicolumn{5}{|c|}{$\begin{array}{l}\text { Data } \\
\text { Date }\end{array}$} & \multirow[t]{2}{*}{$\begin{array}{c}\text { Média } \\
\text { Mean }\end{array}$} & \multirow[t]{2}{*}{$\begin{array}{l}\mathrm{CV} \\
(\%)\end{array}$} \\
\hline & 23/06 & $21 / 07$ & 23/08 & $22 / 09$ & $10 / 10$ & & \\
\hline $\begin{array}{l}\mathrm{LF}^{*} \\
G L B\end{array}$ & $1339^{a}$ & $530^{b}$ & $36^{c}$ & $331^{b}$ & $496^{b}$ & 546,4 & 42,8 \\
\hline $\begin{array}{l}\mathrm{BCV}^{*} \\
L S G S\end{array}$ & $3481^{a}$ & $1808^{b}$ & $107^{c}$ & $346^{\mathrm{C}}$ & $645^{c}$ & 1277,4 & 58,5 \\
\hline $\begin{array}{l}\mathrm{MM}^{*} \\
D M\end{array}$ & $3136^{\mathrm{a}}$ & $1795^{\mathrm{b}}$ & $2065^{b}$ & $1651^{\mathrm{b}}$ & $1104^{b}$ & 1950,2 & 43,4 \\
\hline $\begin{array}{l}\text { LF/BCV } \\
G L B / L S G S\end{array}$ & $0,38^{\mathrm{b}}$ & $0,29^{b}$ & $0,34^{\mathrm{b}}$ & $0,96^{\mathrm{a}}$ & $0,77^{a}$ & 0,55 & 36,9 \\
\hline
\end{tabular}

*LF, BCV e MM em $\mathrm{kg}$ de MS/ha (GLB, GSS, and DM in $\mathrm{kg}$ of DM/ha).

$\mathrm{CV}$ : coeficiente de variação (CV: coefficient of variation).

Médias, na linha, seguidas de diferentes letras diferem $(P<0,05)$ pelo teste Tukey.

Means, within a row, followed by different letters differ $(P<.05)$ by Tukey test.

Tabela 4 - Percentagem de proteína bruta (PB), fibra em detergente neutro (FDN), fibra em detergente ácido (FDA) e nutrientes digestíveis totais (NDT*), nas frações da planta em pastagem de Coastcross, durante o inverno (base matéria seca)

Table 4 - Percentage of crude protein (CP), neutral detergent fiber (NDF), acid detergent fiber (ADF), and total digestible nutrients (TDN) in the plant fractions of Coastcross pasture during the winter (dry matter basis)

\begin{tabular}{|c|c|c|c|c|c|c|c|c|c|c|c|c|}
\hline \multirow[t]{3}{*}{$\begin{array}{l}\text { Data } \\
\text { Date }\end{array}$} & \multicolumn{4}{|c|}{$\begin{array}{c}\mathrm{LF} \\
G L B\end{array}$} & \multicolumn{4}{|c|}{$\begin{array}{l}\text { BCV } \\
L S G S\end{array}$} & \multicolumn{4}{|c|}{$\begin{array}{l}\mathrm{MM} \\
D M\end{array}$} \\
\hline & PB & FDN & FDA & NDT & PB & FDN & FDA & NDT & PB & FDN & FDA & NDT \\
\hline & $C P$ & $N D F$ & $A D F$ & $T D N$ & $C P$ & $N D F$ & $A D F$ & $T D N$ & $C P$ & $N D F$ & $A D F$ & $T D N$ \\
\hline $23 / 06$ & 14,1 & 66,8 & 31,1 & 63,1 & 5,2 & 75,6 & 42,3 & 54,6 & 4,9 & 78,9 & 43,2 & 43,0 \\
\hline 21/07 & 13,9 & 65,1 & 27,2 & 64,0 & 6,4 & 76,4 & 41,9 & 52,0 & 5,2 & 75,1 & 40,0 & 44,5 \\
\hline 23/08 & 26,6 & 54,3 & 23,3 & 67,0 & 6,8 & 74,8 & 42,9 & 48,4 & 5,0 & 82,8 & 46,8 & 43,1 \\
\hline $22 / 09$ & 21,7 & 59,5 & 26,4 & 65,1 & 9,1 & 70,4 & 36,0 & 61,8 & 5,0 & 80,3 & 47,0 & 47,6 \\
\hline $10 / 10$ & 15,7 & 64,0 & 28,3 & 64,7 & 8,0 & 70,4 & 35,2 & 62,4 & 4,9 & 84,4 & 46,5 & 42,0 \\
\hline Média & 18,4 & 61,9 & 27,2 & 64,7 & 7,1 & 73,5 & 39,6 & 55,8 & 5,0 & 80,3 & 44,7 & 44,0 \\
\hline Mean & & & & & & & & & & & & \\
\hline
\end{tabular}

*Estimado de acordo com a equação descrita por Kunkle \& Bates (1998).

* Estimated according to Kunkle \& Bates (1998).

R. Bras. Zootec., v.33, n.3, p.801-810, 2004 
médio foi 7,2 e, apenas nos dois últimos períodos, os valores foram inferiores a 7,0 (em ambos 6,5).

Os valores da $\mathrm{BR}, \mathrm{LF}, \mathrm{BCV}$ e relação $\mathrm{LF} / \mathrm{BCV}$ do pasto formado por Aveia preta e Azevém, são descritos na Tabela 5. Em agosto, foi constatado o menor valor da BR de todo o experimento, o único abaixo de $2000 \mathrm{~kg}$ MS/ha. LF apresentou queda desde o início do experimento até a última amostragem, sendo muito diferente de BCV, que só apresentou queda em agosto. $\mathrm{Na}$ maior parte do período experimental, a relação LF/BCV esteve acima de 0,67 , sendo, no entanto, muito baixa em setembro $(0,33)$ e outubro $(0,26)$.

Observa-se na Figura 2 a percentagem de LF, $\mathrm{BCV}$ e MM da mistura de Aveia + Azevém, detalhando o perfil de cada um desses componentes. LF e MM apresentaram comportamentos diferentes durante os 112 dias avaliados. Enquanto LF representava $50 \%$ do total do pasto no início do experimento, o MM representava menos de 5\%. Com o início do pastejo, o consumo de LF foi muito intenso, reduzindo aproximadamente $76 \%$ até o último mês analisado, enquanto MM tinha sua percentagem aumentada. BCV manteve-se acima de $40 \%$ da composição do pasto em média, apresentando o menor valor em agosto e o maior em setembro.

Os teores de PB, FDN, FDA e NDT da pastagem de Aveia + Azevém são apresentados na Tabela 6 . Utilizando-se os dados de produção de cada componente da planta (Tabela 5) e considerando a composição química de cada um (Tabela 6) pôde-se estimar a composição química da planta inteira, considerando a mistura de Aveia + Azevém.

As médias percentuais de PB da LF, BCV e MM foram de 21,8; 11,3 e 10,2\% e o valor médio para a planta inteira foi de $14,1 \%$, valor inferior ao obtido por Laer \& Maia (1999) e Roso et al. (2000), que encontraram 18 e 20,3\%, respectivamente.

Os valores médios de FDN e FDA para a LF foram os menores $(45,4 \mathrm{e} 25,1 \%)$ e para MM os maiores $(63,4$ e $39,2 \%$ ). A planta inteira teve valores médios de FDN e FDA de 55,5 e 32,2\%, respectivamente.

O NDT médio da planta inteira, mistura de Aveia + Azevém, ficou próximo de 63,3\%. A LF, BCV e MM apresentaram 67,2; 66,1; e 53,2\%, respectivamente, em valores médios. Laer \& Maia (1999) encontraram valores para a planta inteira superiores aos do presente trabalho (78\%), porém, Roso et al. (2000) relatam valores menores $(61 \%)$.

A relação NDT:PB da planta inteira foi de $4,5 \mathrm{em}$ média. Para a LF, esta relação foi menor ainda, sendo de 3,1, em média, indicando grande proporção de proteína em relação à energia disponível.

Durante a primeira fase, os ganhos médios diários (GMD) dos animais suplementados ( $\mathrm{S}=$ suplemento e $\mathrm{SL}=$ suplemento + lasalocida) foram superiores $(\mathrm{P}<0,05)$ aos dos animais que pastejaram Aveia + Azevém (AA). Parte destes elevados ganhos pode ser explicada pelo fenômeno do ganho compensatório, uma vez que, antes do experimento, esses animais não recebiam suplementação e encontravam-se em pastos com baixa disponibilidade de forragem. Entretanto, aspectos importantes a serem considerados foram os elevados valores da LF e BR da pastagem de Coastcross, que possibilitaram oferta adequada de forragem aos novilhos em pastejo.

Ao final do mês de julho, inúmeras geadas atingiram a região, resultando em quedas no GMD dos novilhos dos três tratamentos no período dois, sendo que a menor queda foi promovida por SL, sugerindo que o ionóforo tenha minimizado o estresse pelas condições adversas. As condições críticas dos pastos foram evidenciadas pela grande redução da BR, da $L F$ e da oferta de forragem. Além disso, o acúmulo foi inexistente e o material morto atingiu elevadas proporções (mais de 90\%). Visto que a qualidade da forragem se manteve invariável nos dois primeiros períodos, conclui-se que a diminuição na disponibilidade foi responsável pela queda no desempenho. De

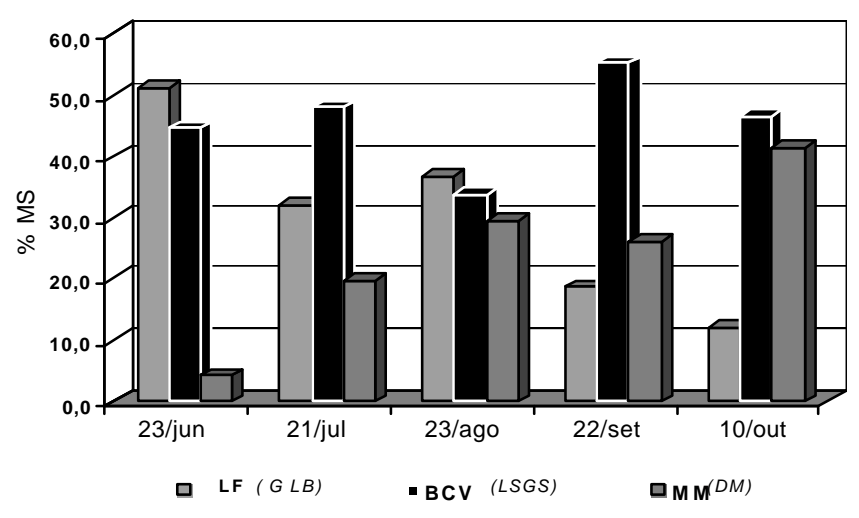

Figura 2 - Proporção dos componentes da mistura de Aveia preta + Azevém: lâmina foliar (LF) bainha + colmo verde (BCV) e material morto (MM).

Figure 2 - Structural components proportion of Oat + Ryegrass mixture: green leaf blade (GLB); leaf sheath + green stem (LSGS) and dead material (DM). 
acordo com Euclides et al. (2001), a biomassa residual é uma combinação da rebrota e da forragem recusada e, como na estação seca a taxa de rebrota é muito baixa, a biomassa residual é, em sua maior parte, composta por plantas ou frações das plantas recusadas pelos animais, o que resulta em uma dieta de menor valor nutritivo para o animal.

Os ganhos médios diários de peso vivo durante todo o período de inverno (112 dias) demonstram a superioridade $(\mathrm{P}<0,05)$ da suplementação e suplementação + lasalocida em relação ao pastoreio em Aveia + Azevém (Tabela 7). Esse desempenho superior apresentado pelos novilhos dos tratamentos
S e SL é decorrente do consumo médio de $3,756 \mathrm{~kg} /$ dia de concentrado, que corresponde ao incremento diário de 0,939 kg de PB e 2,930 kg de NDT à dieta do animal. Comparando esses dados com a composição da mistura de Aveia preta + Azevém, verifica-se que mesmo alimentando-se apenas de LF da pastagem de inverno, os novilhos pastejando AA não alcançaram ingestão diária de PB e NDT igual à dos animais nos tratamentos S e SL.

Euclides et al. (1998), fornecendo para novilhos Nelore na estação seca suplemento composto por $75 \%$ de milho desintegrado com palha e sabugo e $25 \%$ de farelo de soja, encontraram GMD de

Tabela 5 - Biomassa residual (BR), biomassa de lâmina foliar (LF), bainha + colmo verde $(\mathrm{BCV})$, material morto (MM) e a relação LF/BCV da mistura de Aveia preta + Azevém

Table 5 - Residual biomass (RB), green leaf blade (GLB), leaf sheath + green stem (LSGS), dead material biomass (DM), and GLB/LSGS ratio of Oat + Ryegrass mixture

\begin{tabular}{|c|c|c|c|c|c|c|c|}
\hline & & & $\begin{array}{l}\text { Datas } \\
\text { Dates }\end{array}$ & & & $\begin{array}{l}\text { Média } \\
\text { Mean }\end{array}$ & $\begin{array}{l}\mathrm{CV} \\
(\%)\end{array}$ \\
\hline & $23 / 06$ & $21 / 07$ & $23 / 08$ & $22 / 09$ & $10 / 10$ & & \\
\hline $\mathrm{BR}^{*}$ & $2201^{\mathrm{a}}$ & $2047^{a}$ & $1557^{a}$ & $2259^{a}$ & $2404^{a}$ & 2094 & 49,3 \\
\hline $\begin{array}{l}R B \\
\mathrm{LF}^{*}\end{array}$ & $1127^{\mathrm{a}}$ & $660^{b}$ & $570^{\mathrm{b}}$ & $422^{b}$ & $291^{b}$ & 614 & 59,9 \\
\hline $\begin{array}{l}G L B \\
\mathrm{BCV}^{*} \\
L S G S\end{array}$ & $982^{\mathrm{a}}$ & $983^{a}$ & $527^{\mathrm{a}}$ & $1249^{a}$ & $1118^{a}$ & 972 & 61,3 \\
\hline $\begin{array}{l}\mathrm{MM}^{*} \\
D M\end{array}$ & $92^{c}$ & $404^{b c}$ & $460^{b}$ & $588^{\mathrm{b}}$ & $995^{\mathrm{a}}$ & 508 & 53,7 \\
\hline $\begin{array}{l}\mathrm{LF} / \mathrm{BCV} \\
G L B / L S G S\end{array}$ & $1,15^{\mathrm{a}}$ & $0,67^{b}$ & $1,08^{\mathrm{a}}$ & $0,33^{\mathrm{b}}$ & $0,26^{\mathrm{b}}$ & 0,70 & 48,5 \\
\hline
\end{tabular}

*BR, LF, BCV e MM em kg de MS/ha (RB, GLB, LSGS and DM in kg of DM/ha).

$\mathrm{CV}$ : coeficiente de variação ( $C V$ : coefficient of variation).

Médias, na linha, seguidas de diferentes letras diferem $(P<0,05)$ pelo teste Tukey.

Means, within a row, followed by different letters differ $(P<.05)$ by Tukey test.

Tabela 6 - Porcentagem de proteína bruta (PB), fibra em detergente neutro (FDN), fibra em detergente ácido (FDA) e nutrientes digestíveis totais (NDT*), dos componentes da mistura de Aveia preta + Azevém (base matéria seca)

Table 6 - Percentage of crude protein (CP), neutral detergent fiber (NDF), acid detergent fiber (ADF), and total digestible nutrients (TDN) of Oat + reygrass mixture components (dry matter basis)

\begin{tabular}{|c|c|c|c|c|c|c|c|c|c|c|c|c|}
\hline \multirow[t]{3}{*}{$\begin{array}{l}\text { Data } \\
\text { Date }\end{array}$} & \multicolumn{4}{|c|}{$\begin{array}{c}\mathrm{LF} \\
G L B \\
\end{array}$} & \multicolumn{4}{|c|}{$\begin{array}{l}\text { BCV } \\
L S G S\end{array}$} & \multicolumn{4}{|c|}{$\begin{array}{c}\mathrm{MM} \\
D M \\
\end{array}$} \\
\hline & PB & FDN & FDA & NDT & PB & FDN & FDA & NDT & PB & FDN & FDA & NDT \\
\hline & $C P$ & $N D F$ & $A D F$ & $T D N$ & $C P$ & $N D F$ & $A D F$ & $T D N$ & $C P$ & $N D F$ & $A D F$ & $T D N$ \\
\hline $23 / 06$ & 20,9 & 43,5 & 24,5 & 67,4 & 11,4 & 55,0 & 33,5 & 67,5 & 10,9 & 60,5 & 37,3 & 55,4 \\
\hline $21 / 07$ & 18,7 & 41,0 & 22,5 & 68,6 & 11,5 & 58,6 & 29,8 & 65,6 & 9,1 & 60,4 & 36,8 & 56,7 \\
\hline $23 / 08$ & 25,2 & 45,5 & 24,5 & 68,0 & 12,3 & 52,2 & 29,6 & 68,3 & 10,7 & 69,3 & 42,0 & 51,2 \\
\hline $22 / 09$ & 20,7 & 46,7 & 27,2 & 67,1 & 10,6 & 59,7 & 35,3 & 66,3 & 10,1 & 63,7 & 39,5 & 52,0 \\
\hline $10 / 10$ & 23,5 & 50,5 & 27,0 & 65,1 & 10,9 & 62,8 & 36,7 & 63,1 & 10,2 & 64,3 & 40,7 & 50,8 \\
\hline Média & 21,8 & 45,4 & 25,1 & 67,2 & 11,3 & 57,6 & 32,9 & 66,1 & 10,2 & 63,4 & 39,2 & 53,2 \\
\hline
\end{tabular}

*Estimado de acordo com a equação descrita por Kunkle \& Bates (1998).

*Estimated according Kunkle \& Bates (1998).

R. Bras. Zootec., v.33, n.3, p.801-810, 2004 
Tabela 7 - Ganho médio diário (kg/dia) de novilhos em pastagem de Coastcross com suplementação durante o inverno

Table 7 - Average daily gain $(\mathrm{kg} / \mathrm{d})$ of steers in Coastcross pasture, with supplementation during the winter

\begin{tabular}{|c|c|c|c|c|c|}
\hline \multirow[t]{2}{*}{$\begin{array}{l}\text { Tratamento } \\
\text { Treatment }\end{array}$} & \multicolumn{4}{|c|}{$\begin{array}{l}\text { Datas } \\
\text { Dates }\end{array}$} & \multirow[t]{2}{*}{$\begin{array}{l}\text { Média } \\
\text { Mean }\end{array}$} \\
\hline & $21 / 07$ & $18 / 08$ & $15 / 09$ & $13 / 10$ & \\
\hline S & $1,500^{\mathrm{a}}$ & $0,607^{\mathrm{a}}$ & $1,076^{\mathrm{a}}$ & $1,063^{\mathrm{a}}$ & $1,062^{\mathrm{a}}$ \\
\hline SL & $1,610^{\mathrm{a}}$ & $0,799^{a}$ & $0,754^{\mathrm{a}}$ & $0,938^{a}$ & $1,025^{\mathrm{a}}$ \\
\hline AA & $1,120^{b}$ & $0,357^{\mathrm{a}}$ & $0,871^{\mathrm{a}}$ & $1,080^{\mathrm{a}}$ & $0,856^{b}$ \\
\hline OR & & & & & \\
\hline Média & 1,410 & 0,588 & 0,900 & 1,027 & 0,981 \\
\hline Mean & & & & & \\
\hline $\mathrm{CV}$ & 20,59 & 30,98 & 20,58 & 20,72 & \\
\hline
\end{tabular}

S: suplementação; SL: suplementação + lasalocida; AA: pastoreio em aveia + azevém. (S: supplementation; SL: supplementation + lasalocid; OR: Oat + Ryegrass grazing). $\mathrm{CV}$ : coeficiente de variação (CV: coefficient of variation).

Médias na coluna com letras diferentes são diferentes $(P<0,05)$ pelo teste Tukey.

Means, within a column, followed by different letters differ $(P<.05)$ by Tukey test.

$1,062 \mathrm{~kg} / \mathrm{dia}$, muito próximos ao do presente trabalho $(1,030 \mathrm{~kg} / \mathrm{dia})$, mesmo utilizando níveis mais baixos de suplemento $(0,8 \%)$, porém, impondo menor taxa de lotação $(0,87$ x 2,0 UA/ha). Na estação seca, no segundo ano de experimento, os autores observaram GMD de $0,520 \mathrm{~kg} / \mathrm{dia}$ e esta diminuição, segundo eles, deveu-se à menor percentagem de biomassa de forragem verde, a qual representou 44 e $28 \%$ do total da MS, no primeiro e segundo ano, respectivamente. Elevados GMD de novilhas Nelore $(0,960 \mathrm{~kg} / \mathrm{dia})$ também foram observados por Macedo \& Silva (1999), em ensaio de suplementação em pastagens de Brachiaria brizantha cv. MG4, com biomassa residual de $2540 \mathrm{~kg}$ de $\mathrm{MS} / \mathrm{ha}$ e suplemento contendo $24 \%$ de PB a $0,8 \%$ do PV, entre setembro e novembro.

Suplementando novilhos do mesmo grupo genético do presente trabalho ( $1 / 2$ Red Angus $1 / 2$ Nelore) em pastagens de Brachiaria decumbens, na estação seca, Euclides et al. (2001) forneceram suplemento contendo $19,1 \%$ de PB e $71,5 \%$ de NDT, a $0,8-0,9 \%$ do PV, e observaram GMD de $0,495 \mathrm{~kg} / \mathrm{dia}$, com taxa de lotação média de 1,35 UA/ha, durante dois anos de observação. Salienta-se que, nos tratamentos do presente experimento, a carga animal foi sempre mais elevada que as relatadas nos estudos citados anteriormente, o que em produção/ha, poderia resultar em valores muito maiores.

Mesmo com resultado inferior aos demais tratamentos, AA alcançou elevado GMD durante todo o experimento $(0,856 \mathrm{~kg} / \mathrm{dia})$, sendo superior ao observado por Roso \& Restle (2000), que relataram ganhos de 0,679 kg/dia, por animais de sete meses de idade em pastejo na mistura de Aveia + Azevém, entre os meses de maio e novembro.

A adição de lasalocida ao suplemento não incrementou $(\mathrm{P}>0,05)$ o desempenho dos animais, confirmando as observações de Hubbel et al. (1992) sobre o desempenho de novilhos alimentados com feno de capim-bermuda (Cynodon dactylon (L.) Pers) e ração concentrada.

\section{Conclusões}

Novilhos cruzados mantidos em pasto de Coastcross tiveram desempenho superior a $0,85 \mathrm{~kg}$ / dia durante o inverno, quando manejados com pastejo horário (quatro horas/dia) em áreas com Aveia + Azevém e, ganhos ainda mais elevados (acima de $1 \mathrm{~kg} / \mathrm{dia}$ ) foram verificados com a suplementação em $1,2 \%$ do PV, com o uso de ração concentrada, não havendo resposta à adição da lasalocida.

\section{Literatura Citada}

CAMPBELL, A.G. Grazed pastures parameters; I. Pasture drymatter production and availability in a stocking rate and grazing management experiment with dairy cows. Journal of Agriculture Science, v.67, p.211-216, 1966.

CARVALHO, P.C.F.; RIBEIRO FILHO, H.M.N.; POLI, C.H.E.C. et al. Importância da estrutura da pastagem na ingestão e seleção de dietas pelo animal em pastejo. In: A PRODUÇÃO ANIMAL NA VISÃO DOS BRASILEIROS, 2001, Piracicaba. Palestras... Piracicaba: Fundação de Estudos Agrários Luiz de Queiroz, 2001. p.927. 
CORSI, M.; MARTHA JR., G. B. Manejo de pastagens para produção de carne e leite. In: SIMPÓSIO SOBRE MANEJO DA PASTAGEM, 15., 1998, Piracicaba. Palestras... Piracicaba: Fundação de Estudos Agrários Luiz de Queiroz, 1998. p.296.

DELCURTO, T.; COCHRAN, R.C.; CORAH, L.R. et al. Supplementation of dormant tallgrass-prairie forage: II. Performance and forage utilization characteristics in grazing beef cattle receiving supplements of different protein concentrations. Journal of Animal Science, v.68, n.2, p.532-542, 1990.

EUCLIDES, V.P.B.; EUCLIDES FILHO, K.; COSTA, F.P. et al. Desempenho de novilhos F1s Angus-Nelore em pastagens de Brachiaria decumbens submetidos a diferentes regimes alimentares. Revista Brasileira de Zootecnia, v.30, p.470-481, 2001 .

EUCLIDES, V.P.B.; EUCLIDES FILHO, K.; COSTA, F.P. et al. Desempenho de novilhos em pastagens de Brachiaria decumbens submetidos a diferentes regimes alimentares. Revista Brasileira de Zootecnia, v.27, p.246-254, 1998.

GARDNER, A.L. Técnicas de pesquisa em pastagens e aplicabilidade de resultados em sistemas de produção. Brasília: IICA/EMBRAPA-CNPGL, 1986. 197p (Série publicações miscelâneas, 634).

GARMAN, C.L.; HOLDEN, L.A.; KANE, H.A. Comparison of in vitro dry matter digestibility of nine feedstuffs using three methods of analysis. Journal of Dairy Science, v.80 (supplement 1), p.260, 1997.

HUBBEL, D.S.; GOETSCH, A.L.; GALLOWAY, D.L. et al. Digestion and performance responses to lasalocid and concentrate supplements by beef cattle fed bermudagrass hay. Arch Tierernahr, v.42, p.79-92, 1992.

KUNKLE, W.E.; BATES, D.B. Evaluating feed purchasing options: energy, protein, and mineral supplements. In: FLORIDA BEEF CATTLE SHORT COURSE, 1998, Gainesville. Proceedings... Gainesville: University of Florida, 1998. p.59-70.

LAER, R.R.V.; MAIA, M.S. Produção e qualidade de forragem da mistura Aveia preta Azevém anual em dois anos no sistema de plantio direto. In: REUNIÃO ANUAL DA SOCIEDADE BRASILEIRA DE ZOOTECNIA, 36., 1999, Porto Alegre. Anais... São Paulo: SBZ/Gnosis, [1999] 17par. CD-ROM. Forragicultura. Qualidade e valor nutritivo. FOR-076.

MACEDO, M.P.; SILVA, M.V.G.B. Efeito da suplementação no desempenho de novilhas de corte em pastagens na época da seca. In: REUNIÃO ANUAL DA SOCIEDADE BRASILEIRA DE ZOOTECNIA, 36, 1999, Porto Alegre. Anais... São Paulo: SBZ/Gnosis, [1999] 17par. CD-ROM. Nutrição de ruminantes. Bezerros e gado leiteiro. NUR-013.

MARASCHIN, G.E. Premissas e perspectivas da avaliação de pastagens. In: REUNIÃO ANUAL DA SOCIEDADE BRASILEIRA DE ZOOTECNIA, 36., 1999, Porto Alegre. Palestras... São Paulo: SBZ/Gnosis, [1999] 17par. CD-ROM.

MOORE, J.E.; KUNKLE, W.E. Balancing protein and energy in forages. In: FLORIDA BEEF CATTLE SHORT COURSE, 1998, Gainesville. Proceedings... Gainesville: University of Florida, 1998. p.126.

MOORE, J.E.; KUNKLE, W.; BROWN, W.F. Forage quality and the need for protein and energy supplements. In: FLORIDA BEEF CATTLE SHORT COURSE, 1991. Gainesville. Proceedings... Gainesville: University of Florida, 1991. p.196.
NUSSIO, L.G.; MANZANO, R.P.; PEDREIRA, C.G.S. Valor alimentício em plantas do gênero Cynodon. In: SIMPÓSIO SOBRE MANEJO DA PASTAGEM, 15., 1998, Piracicaba. Palestras... Piracicaba: Fundação de Estudos Agrários Luiz de Queiroz, 1998. p.296.

PEDREIRA, C.G.S.; MELLO, A.C.L.; OTANI, L. O processo de produção de forragem em pastagens. In: A PRODUÇÃO ANIMAL NA VISÃO DOS BRASILEIROS, 2001, Piracicaba. Palestras... Piracicaba: Fundação de Estudos Agrários Luiz de Queiroz, 2001. p.927.

PERUCHENA, C.O. Suplementación de bovinos para carne sobre pasturas tropicales, aspectos nutricionales, productivos y economicos. In: REUNIÃO ANUAL DA SOCIEDADE BRASILEIRA DE ZOOTECNIA, 36, 1999, Porto Alegre. Palestras... São Paulo: SBZ/Gnosis, [1999] 17par. CD-ROM.

RAUEN, M.J.; SÁ, J.C.M.; OLIVEIRA, E.F. Forragicultura no Paraná. 1.ed. Londrina: Universidade Estadual de Londrina, 1996. 305p.

ROSO, C.; RESTLE, J.; SOARES, A.B. et al. Aveia preta, triticale e centeio em mistura com Azevém. 1. Dinâmica, produção e qualidade de forragem. Revista Brasileira de Zootecnia, v.29, p.75-84, 2000.

ROSO, C.; RESTLE, J. Aveia preta, triticale e centeio em mistura com Azevém. 2. Produtividade animal e retorno econômico. Revista Brasileira de Zootecnia, v.29, p.85-93, 2000.

SECRETARIA DA AGRICULTURA E DO ABASTECIMENTO DO ESTADO DO PARANÁ. “Paraná cidade: Luiziana”, 2000. http://www.paranacidade.org.br/base/ municipio.asp (04/02/2002)

SILVA, D.J. Análise de alimentos (métodos químicos e biológicos). 2.ed. Viçosa, MG: Universidade Federal de Viçosa, 1990. 165 p.

THIAGO, L.R.L.S. “Suplementação de Bovinos em pastejo - aspectos práticos para seu uso na mantença e ganho de peso”, 1999. http://www.cnpgc.embrapa.br/publicacoes/ naoseriadas/suplementhiago (14/10/2000).

TILLEY, J.M.A.; TERRY, R.A. A two stage technique for the "in vitro" digestion of forage crop. Journal of Britain Grassland Society, v.18, p.104-111, 1963.

Van SOEST, P.J.; ROBERTSON, J.B.; LEWIS, B.A. Methods for dietary fiber, and non-starch polysaccharides in relation to animal nutrition. Journal of Dairy Science, v.74, p.35833597, 1991.

VILELA, D.; ALVIM, M.J. Manejo de pastagens do gênero Cynodon: introdução, caracterização e evolução do uso no Brasil. In: SIMPÓSIO SOBRE MANEJO DA PASTAGEM, 15, 1998, Piracicaba. Palestras... Piracicaba: Fundação de Estudos Agrários Luiz de Queiroz, 1998. p.296.

WILM, H.G.; COSTELO, O.F.; KLIPPLE, G.E. Estimating forage yield by the double sampling method. Journal of American Society of Agronomy, v.36, p.194-203, 1949. 